\title{
Endoftalmitis y abscesos cerebrales múltiples en un paciente con endocarditis por Streptococcus agalactiae
}

\author{
D. PEÑA JIMÉNEZ, J. DE LA TORRE LIMA, J. L. PRADA PARDAL, F. POVEDA \\ GÓMEZ, J. J. GARCÍA ALEGRÍA
}

Servicio de Medicina Interna. Hospital Costa del Sol. Marbella. Málaga

\begin{abstract}
RESUMEN
La endoftalmitis endógena es una rara entidad asociada a diseminación bacteriana hematógena desde un foco séptico interno.

Las infecciones en adultos causadas por Streptococcus agalactiae son muy infrecuentes aunque cada vez se describen más casos, sobre todo en relación a situaciones de inmunodepresión.

Presentamos un caso excepcional de endocarditis por Streptococcus agalactiae que se complicó con abscesos cerebrales múltiples y endoftalmitis. Asimismo revisamos la literatura publicada al respecto.
\end{abstract}

PALABRAS CLAVE: Endoftalmitis. Streptococcus agalactiae. Endocarditis. Absceso cerebral.

\author{
ENDOPHTHALMITIS AND MULTIPLE BRAIN ABSCESS IN A \\ PATIENT WITH ENDOCARDITIS DUE TO STREPTOCOCCUS AGA- \\ LACTIAE
}

\begin{abstract}
Endogenous endophthalmitis is a rare disease caused by hematoge nic germ spread from an internal focus. Infections due to Streptococcus agalactiae are infrequent in adults althought new cases had been descri bed recently associated to inmunodepression.

We present a patient with endocarditis due to Streptococcus agalactiae, endophthalmitis and multiple brain abscess. We also review the lite rature.
\end{abstract}

KEY WORDS: Endophthalmitis. Streptococcus agalactiae. Endocardi tis. Brain abscess.

Peña Jiménez D, De la Torre Lima J, Prada Pardal JL, Poveda Gómez. F, García Alegría JJ. Endoftalmitis y abscesos cerebrales múltiples en un paciente con endocarditis por Streptococcus agalactiae. An Med Interna (Madrid) 2001; 18: 379-380.

\section{INTRODUCCIÓN}

La endoftalmitis bacteriana suele producirse como complicación de una intervención quirúrgica craneofacial o tras traumatismo ocular. En muy raras ocasiones el origen es endógeno $(1,2)$. En estos casos los microorganismos pueden proceder prácticamente de cualquier región anatómica, aunque las más descritas son: tracto urinario, meninges, corazón, partes blandas y tracto digestivo $(1,2)$. La endocarditis infecciosa es por tanto una causa descrita aunque excepcional de endoftalmitis endógena (2). Por otro lado, hasta un $40 \%$ de casos de endocarditis infecciosa se acompaña de alteraciones neurológicas $(3,4)$. Clínicamente suele corresponder a episodios de accidente cerebrovascular sin componente hemorrágico $(50 \%$ de los pacientes) $(3,4)$. Presentamos el caso de un paciente con endocarditis mitral por Streptococcus agalactiae que debutó con fiebre y endoftalmitis aguda unilateral compli- cándose posteriormente con cuadro de encefalopatía por abscesos cerebrales múltiples.

\section{CASO APORTADO}

Varón de 51 años con antecedentes de hepatopatía crónica etílica estadio B de Child-Pugh, hipertensión portal y diabetes mellitus tipo II en tratamiento con glibenclamida. El paciente acude a Urgencias por cefalea intensa hemicraneal derecha, dolor en globo ocular ipsilateral, exoftalmos y disminución de la agudeza visual. Estaba en tratamiento con AINEs y ciprofloxacino desde varios días antes por sospecha de infección urinaria. En la exploración destaca fiebre de $38,6^{\circ}$, tendencia al sueño, y desorientación temporo-espacial, hepatomegalia $2-3 \mathrm{~cm}$ indolora, sin ascitis, rigidez nucal, exoftalmos derecho y Babinsky bilateral. Agudeza visual de percepción de la luz en ojo derecho, polo anterior con quemosis, ingurgitación vascular, edema corneal, hipopion y membrana ciclítica. Ojo izquierdo sin alteraciones. En las complementarias destacaba hemocultivos positivos

Trabajo aceptado: 16 de Enero de 2000

Correspondencia: Daniel Peña Jiménez: Avda. García Lorca, Urb. Pueblo Quinta, $5^{\text {a }}$ fase, bloque 1, $3^{\circ}$ A. 29630 - Benalmádena Costa. Málaga 
para Streptococcus agalactiae en 4 tomas, liquido cefalorraquídeo con glucosa $204 \mathrm{mg} / \mathrm{dl}$, proteínas $153 \mathrm{mg} / \mathrm{dl}$, leucocitos 190 por milímetro cúbico (52\% polimorfonucleares), 320 hematíes por milímetro cúbico y cultivo negativo. Rx tórax con ICT aumentado. TAC cráneo con varias lesiones de pequeño tamaño captadoras de contraste y tamaño inferior a $1 \mathrm{~cm}$ localizadas en cerebelo y en ambos hemisferios de predominio periférico con edema perilesional. Ecocardiograma: vegetación de $6 \mathrm{~mm}$ en valva posterior mitral.

Se instauró tratamiento con ampicilina, vancomicina y ceftacidima; tratamiento oftalmológico con ciclopléjicos, tobrex colirio (tobramicina), maxitrol colirio (neomicina, dexametasona, polimixina B) y vancomicina intravítrea $1 \mathrm{mg} / 0,1 \mathrm{ml}$. El paciente mejoró ini cialmente pero a las 48 horas presenta cuadro confusional agudo con disminución del nivel de conciencia y fiebre elevada. Se considera que el cuadro se debe a embolismos sépticos repetitivos por lo que se deriva para sustitución valvular urgente, falleciendo en el postoperatorio inmediato. No se autorizó la necropsia.

\section{DISCUSIÓN}

Los estreptococos del grupo B se reconocen como una causa cada vez mas frecuente de enfermedad invasiva en adultos (5-8). Las localizaciones más frecuentes son la piel, tejidos blandos, bacteriemia sin foco, hueso, tracto urinario y aparato respiratorio (5-8). Se asocia a una serie de factores predisponentes como diabetes mellitus, neoplasias malignas, enfermedades hepáticas y aquellos procesos que cursan con cierto grado de inmunodepresión como alcoholismo, desnutrición y drogadicción parenteral (1,5,7-9). La endocarditis por Strep tococcus agalactiae es extremadamente rara, suele producirse en válvulas izquierdas (sobre todo la aórtica) y se asocia a un curso agresivo con embolizaciones frecuentes y alta mortalidad, obligando en la mayoría de los casos a un tratamiento quirúrgico precoz $(5,6,8)$.Las endoftalmitis endógenas suelen estar causadas por gérmenes gram positivos (dos tercios de los casos) asociándose a mejor pronóstico que las infecciones por gram negativos $(1,2)$. El grupo de los estreptococos es el más frecuente $(32 \%)$ siguiéndole el grupo de los estafilococos $(25 \%)$ sobre todo a expensas del Stafilococcus aureus $(1,2)$. Dentro de los estreptococos destacan por orden de frecuencia los del grupo viridans, enterococos y neumococos $(1,10)$. En nuestro paciente el germen aislado fue un Streptococcus aga lactiae que es considerado un hallazgo excepcional (10). Existe consenso en el tratamiento de la endoftalmitis con antibióticos parenterales, corticoides y antibióticos tópicos así como intravítreos. Algunos autores preconizan incluso la realización de vitrectomía $(1,2)$. A pesar de todo, las endoftalmitis endógenas se asocian a un mal pronóstico de agudeza visual ya que más de las tres cuartas partes de los pacientes pierden la visión a pesar de un diagnóstico y tratamiento precoces $(1,2,9)$. Las complicaciones neurológicas acontecen en un $10-40 \%$ de los casos de endocarditis infecciosas y se asocian a un aumento de la tasa de mortalidad $(3,4)$. El proceso más frecuente es el ACV embólico no hemorrágico (50\% casos) $(3,4)$. Nuestro paciente inició un cuadro de encefalopatía brusca que, aunque descrita en la literatura, es muy infrecuente (4). El tratamiento de elección de la endocarditis es la antibioterapia durante 4-6 semanas (4). El recambio valvular quirúrgico se debe realizar siempre en el caso de válvula protésica. En el caso de válvula nativa se debe realizar sin demora cuando existe fallo terapéutico con inestabilidad hemodinámica, sepsis persistente o embolismos recurrentes, extensión de las lesiones cardiacas con formación de abscesos, alteraciones de la conducción o fístulas, alteraciones neurológicas del tipo meningitis aguda, accidente isquémico transitorio, encefalopatía o convulsiones sin lesiones cerebrales en el TAC, endocarditis por hongos, Stafilococcus aureus y gérmenes gram negativos (4). Cuando el recambio valvular se realiza muy cercano en el tiempo al evento neurológico agudo, las probabilidades de que surjan complicaciones son muy elevadas $(3,4)$. En nuestro caso la aparición de encefalopatía llevó al recambio valvular urgente, falleciendo el paciente en el postoperatorio inmediato. Como conclusiones prácticas de este caso podríamos destacar que: a) ante una endoftalmitis sin antecedentes de cirugía local ni traumatismo craneofacial previo estamos obligados a descartar un foco séptico (por ejemplo una endocarditis); b) llamar la atención sobre el comportamiento agresivo de las endocarditis causadas por Strep tococcus agalactiae, que a pesar de ser muy infrecuentes, obligan a un tratamiento agresivo, una vigilancia extrema y una consulta quirúrgica precoz.

\section{Bibliografía}

1. Okada A, Johnson RP, Liles WC, D’Amico DJ, Baker AS. Endogenous bacterial endophthalmitis. Report of a ten year retrospective study. Ophthalmology 1994 May; 101 (5): 832-38.

2. De Otero J, Almirante B, Ribera E, Tornos MP. Endoftalmitis secundaria a endocarditis bacteriana (carta). Med Clin 1995; 105 (18): 717-18.

3. Ting W, Silverman N, Levitsky S. Valve replacement in patients with endocarditis and cerebral septic emboli. Ann Thorac Surg 1991; 51 (1): $18-22$.

4. Gillinov AM, Stuart RS, Cameron DE, Baumgartner WA, Greene PS. Surgical management of patients with endocarditis and acute neurologic deficit. Comp Surg 16(9), 1997.

5. Scully BE, Spriggs D, Neu HC. Streptococcus agalactiae (group B) endocarditis, a description of twelve cases and review of the literature. Infection 1987; 15 (3): 169-76.

6. Pringle SD, McCartney AC, Marshall DA, Cobbe SM. Infective endo- carditis caused by streptococcus agalactiae. Int J Cardiol 1989; 24 (2): 179-837.

7. Farley MM. Group B streptococcal infection in older patientes. Spectrum of disease and management strategies. Drugs Aging 1995; 6 (4): 293-300.

8. Schwartz B, Schuchat A, Oxtoby MJ, Cochi SL, Hightower A, Broome $\mathrm{CV}$. Invasive group B streptococcal disease in adults. A populationbased study in metropolitan Atlanta. JAMA 1991; 28; 266 (8): 111214.

9. Magadur G, Raffi F, Bouchut P, Chevalet P, Merrien D, Struillou L, Barrier JH. Hematogenic bacterial endophthalmitis. A rare infection with very poor functional prognosis. Ann Med Interne Paris 1996; 147 (3): 212-17.

10. Mao LK, Flynn HW, Miller D, Pflugfelder SC. Endophthalmitis caused by streptococcal species. Arch Ophthalmol 1992; 110 (6): 798-801. 